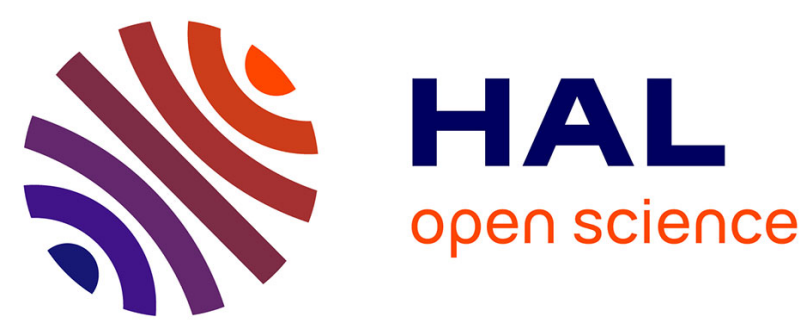

\title{
Packageless temperature sensor based on AlN/IDT/ZnO/Silicon layered structure
}

Ouarda Legrani, Omar Elmazria, Meriem Elhosni, Ausrine Bartasyte, Philippe Pigeat, Sergei Zghoon

\section{- To cite this version:}

Ouarda Legrani, Omar Elmazria, Meriem Elhosni, Ausrine Bartasyte, Philippe Pigeat, et al.. Packageless temperature sensor based on AlN/IDT/ZnO/Silicon layered structure. 2013 IEEE International Frequency Control Symposium, IEEE, Jul 2013, Prague, Czech Republic. 10.1109/EFTFIFC.2013.6702265 . hal-01519286

\section{HAL Id: hal-01519286 \\ https://hal.univ-lorraine.fr/hal-01519286}

Submitted on 6 Sep 2018

HAL is a multi-disciplinary open access archive for the deposit and dissemination of scientific research documents, whether they are published or not. The documents may come from teaching and research institutions in France or abroad, or from public or private research centers.
L'archive ouverte pluridisciplinaire HAL, est destinée au dépôt et à la diffusion de documents scientifiques de niveau recherche, publiés ou non, émanant des établissements d'enseignement et de recherche français ou étrangers, des laboratoires publics ou privés. 


\section{Packageless temperature sensor based on AlN/IDT/ZnO/Silicon layered structure}

\author{
O. Legrani, O. Elmazria, M. Elhosni, A. Bartasyte and \\ P. Pigeat \\ University of Lorraine, Institut Jean Lamour, UMR 7198 \\ Centre National de la Recherche Scientifique (CNRS), \\ Institut Jean Lamour , UMR 7198 \\ 54506 Vandoeuvre-les-Nancy, FRANCE \\ ouarda.legrani@univ-lorraine.fr
}

\begin{abstract}
The possibility to generate simultaneously Surface Acoustic Wave (SAW) and Waveguiding layer acoustic wave (WLAW) in layered structures AIN/ZnO/Silicon was investigated. A delay line operating at $525 \mathrm{MHz}$ was tested versus temperature in air and in contact with liquid. Experimental characterizations were also supported by modeling using the commercial software (COMSOL Multiphysics). The full delay line was simulated and liquid modeled by an additional layer on the top of AIN film.
\end{abstract} $\mathrm{ZnO}$

Keywords- AlN; packageless; silicon; temperature sensor;

\section{INTRODUCTION}

Devices based on wave guiding layer acoustic waves (WLAW) present a great interest in sensor application due to packageless structure, the possibility of extreme miniaturization and reduced sensibility to chemical environment. To generate isolated waves, the structures combining layers with low and high impedance in Bragg mirror configuration (ILAW-Isolated Layer Acoustic Wave) or acoustic confinement of the wave in a low-acoustic-velocity layer between two high-acoustic-velocity materials were used [1]. There are several requirements for the guiding layer: to be highly oriented and to have low surface roughness to ensure a good wave transmission and to avoid the increase of the acoustic propagation losses [2-4]. The isolated layer can be dielectric, piezoelectric or metallic and has to be stress- and crack-free and relatively thick for the confinement of the wave. Electro-acoustic properties of isolated wave, such as propagation velocity and electromechanical coupling are highly dependent on the nature, thickness and geometrical configuration of the materials composing WLAW device.

To this date, few studies have been reported in the literature on this type of structure [1, 5-7]. The successful confinement of WLAW in structures based on $\mathrm{SiO}_{2}$ guiding layer was reported by Zhgoon et al. [1, 7]. However, more efforts need to be done to increase the coupling coefficient of such structures. Due to its low acoustic velocity and its high electromechanical coupling, zinc oxide was one of most promising material for the guiding layer. Our previous works have shown theoretically and experimentally, the possibility to generate Waveguiding

\author{
S. Zghoon \\ National Research University \\ "Moscow Power Engineering Institute" \\ 14 Krasnokazarmennaja, \\ 111250 Moscow, Russia
}

layer acoustic wave in layered structures $\mathrm{AlN} / \mathrm{ZnO} /$ diamond [8]. Such structures are of great interest because of their potential applications as packageless resonators, filters or sensors, based on WLAW, and as thermally compensated gas or liquid sensors, based on the combination of both SAW and WLAW. Because of its high acoustic velocity, the diamond appears to be the most suitable substrate for the production of containment structures for WLAW wave type, but it has major drawbacks including its high price and its poor compatibility with CMOS technology. In addition, the diamond growth occurs at high temperatures $\left(700{ }^{\circ} \mathrm{C}-1000{ }^{\circ} \mathrm{C}\right)$ inducing significant stress in the heterostructure. Therefore heterostructures with diamond are unsuitable for mass production.

The aim of this work is to evidence the potential of the AlN/ZnO/Silicon structure as low cost, CMOS compatible and packageless temperature sensor able to operate in harsh environments. Theoretical investigation was realized by using a finite element method (FEM) in order to define the best configuration and the optimized thicknesses of different layers. To achieve efficient confinement of WLAW, AlN layer was deposited on operating SAW device (IDT/ZnO/Si). The frequency response and thickness of AlN were monitored in real-time and during AlN film deposition. The second part of this paper is devoted to the experimental realization of the heterostructure with a comparison of results obtained by the simulation.

\section{THEORITICAL DETAILS}

Theoretical investigation was realized by a finite element method (FEM) using COMSOL Multiphysics [9]. The full delay line was simulated and liquid was modeled by an additional layer on the top of the AlN film.

$\mathrm{kh}_{\mathrm{ZnO}}=1.25$ has been chosen i.e. $(\lambda=10 \mu \mathrm{m}$, thickness $(\mathrm{ZnO})$ $=2 \mu \mathrm{m}$, thickness $(\mathrm{AlN})>20 \mu \mathrm{m})$.

The materials are described by their physical constants (elastic, piezoelectric, dielectric...), reported in literature [10-12].

The confinement of the wave was demonstrated by analyzing the field distribution of the wave in the structure notably the acoustic wave displacement profile. 


\section{EXPERIMENTAL SETUP}

$2 \mu \mathrm{m}$ thick $\mathrm{ZnO}$ films were deposited on $\mathrm{Si}$ (100) by $\mathrm{rf}$ magnetron sputtering. The pressure in the chamber was 0.002 mbar $\left(1: 1\right.$ of $\left.\mathrm{Ar}: \mathrm{O}_{2}\right)$ and the power injected in the plasma was $100 \mathrm{~W}$. The distance target-substrate was fixed at $80 \mathrm{~mm}$ and the substrate temperature was $450^{\circ} \mathrm{C}$. Then IDT were fabricated on $\mathrm{ZnO} / \mathrm{Si}$ surface by using Aluminum sputtering followed by photolithography and wet etching processes. The number of IDT fingers, the aperture width (W) and the gap were set to $40,0.4 \mathrm{~mm}$ and $200 \mu \mathrm{m}$, respectively. Finally, 30 $\mu \mathrm{m}$ of AlN were deposited on IDT/ZnO/Si by rf magnetron sputtering. AlN deposition process was optimized to avoid the AlN film cracking even in the case of thick layer. Following our experience, the key consists in working at relatively low deposition temperature $(343 \mathrm{~K})$. To perform electrical characterization, vacuum tight $\mathrm{rf}$ connectors were installed in the magnetron vacuum chamber. During AIN layer deposition, in-situ measurements of frequency and insertion losses of different modes were performed by a network analyzer (Agilent N5230A) and AlN thickness was monitored by interferential reflectometry method.

\section{RESULTS AND DISCUSSION}

1D-curves and $2 \mathrm{D}$ representation of modeling results for the particles displacement in $\mathrm{AlN} / \mathrm{ZnO} / \mathrm{Si}$ hétérostructure obtained for $2 \mu \mathrm{m}$ and $12 \mu \mathrm{m}$ of AlN thickness are shown in Fig.1 (a) and (b). The AlN thickness influences the confinement of the wave. Indeed, one can clearly observe that with $2 \mu \mathrm{m}$ of AlN, the displacement of particles was reduced at the surface that corresponds to $30 \%$ of confinement, at $12 \mu \mathrm{m}$ of AlN zero displacement of particle was observed resulting in a total confinement of the wave. The addition of liquid on top of the AlN film in modeling induces no serious change in transmission signal that proves theoretically the confinement of the wave (Fig. 1(c)). The evolution of frequency response in transmission mode $\left(S_{21}\right)$, obtained experimentally, related to the $0^{\text {th }}, 1^{\text {st }}$ and $2^{\text {nd }}$ mode of acoustic wave, with AIN layer thickness is shown in Fig. 4. Before AlN deposition, only the $1^{\text {st }}$ mode was observed due to the low electromechanical coupling of the other mode. At $12 \mu \mathrm{m}$ of AlN thickness, the mode 1 starts to confine and the surface acoustic wave of $2^{\text {nd }}$ mode appears. Frequency-Temperature characteristic shows a
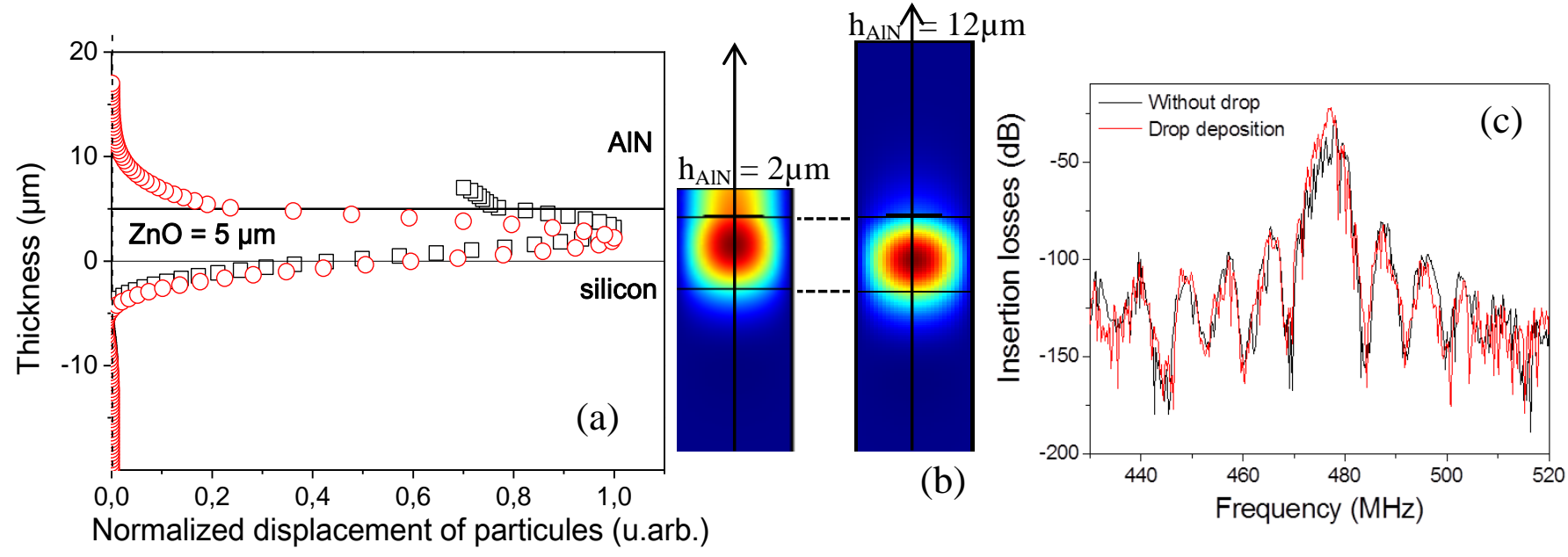

Fig.1: (a) 1D-curves and (b) 2D representation of modeling of the displacement of particles in AlN/ZnO/Si heterostructure obtained for $2 \mu \mathrm{m}$ and $12 \mu \mathrm{m}$ of AlN thickness. (c) Transmission signal of a delay-line obtained by modeling in air and with water over-layer.
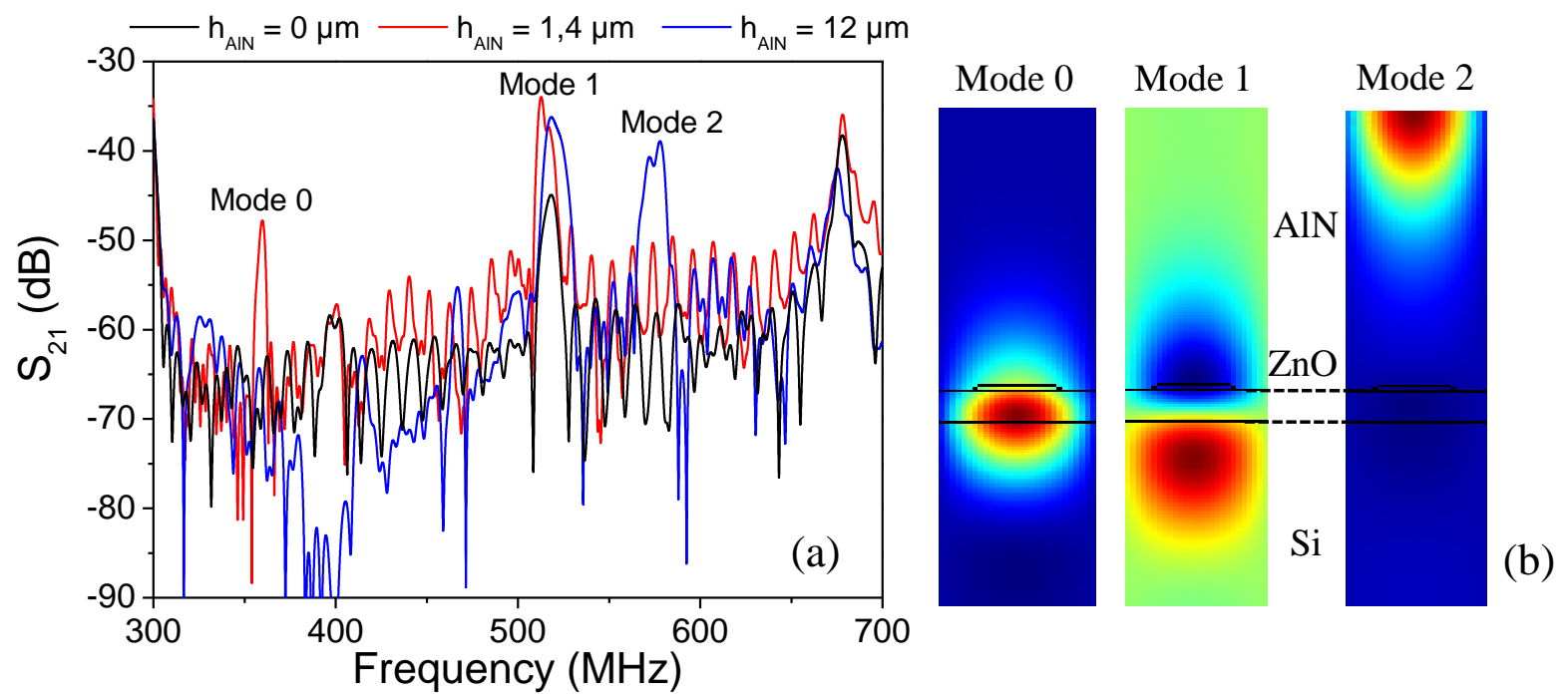

Fig. 2: (a) SAW signal $\left(\mathrm{S}_{21}\right)$ before and after deposition of AlN with the thickness of 1.4 and $12 \mu \mathrm{m}$ for the heterostructure AlN / ZnO / Si where $\mathrm{kh}_{\mathrm{ZnO}}=1.25$. (b) $2 \mathrm{D}$ representation of modeling results for particle displacement in $\mathrm{AlN} / \mathrm{ZnO} / \mathrm{Si}$ hétérostructure obtained for $12 \mu \mathrm{m}$ of AlN thickness for the mode 0,1 and 2 . 


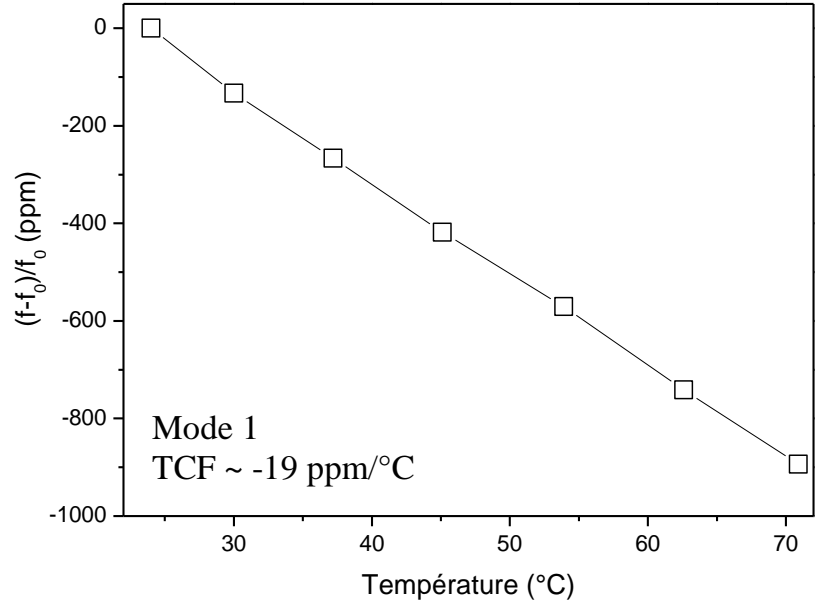

Fig 3: Relative velocity variation with temperature of $\mathrm{AlN} / \mathrm{ZnO} / \mathrm{Si}$ structure.

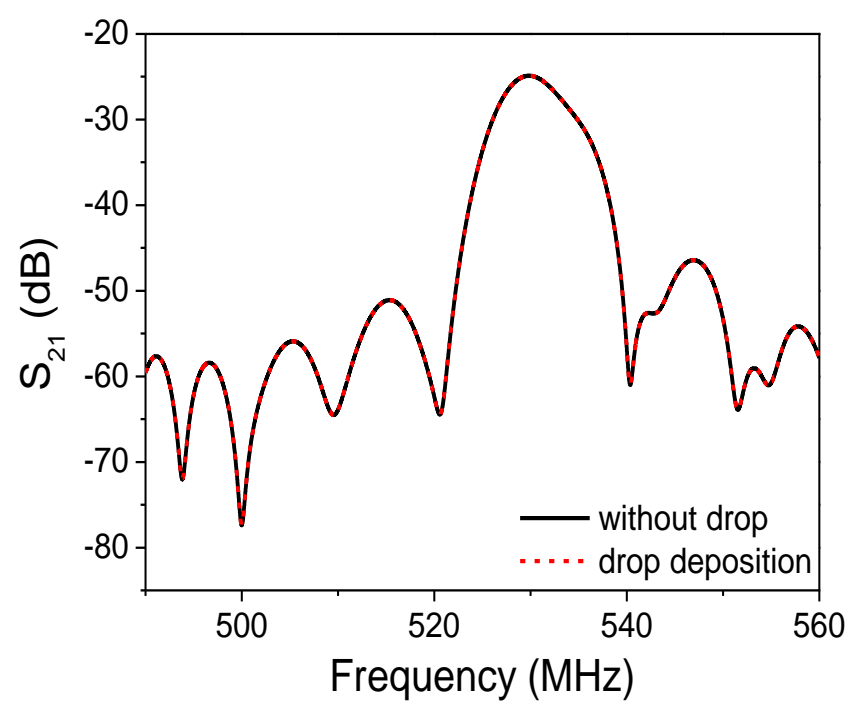

Fig. 4: Experimental test of the wave's confinement with addition of a water micro drop on the gap between the IDTs of the device.

very good linearity and a TCF value of $-19 \mathrm{ppm} /{ }^{\circ} \mathrm{C}$ in air and in contact with liquid (Fig. 3). One can also observe that there is no change in transmission responses $\left(S_{21}\right)$ collected in both conditions (Fig. 4). These results prove the total confinement of the wave in the AlN/IDT/ZnO/Si structure. Note that a Rayleigh wave on open surface is partially or completely attenuated. This study confirmed the feasibility of the AlN/IDT/ ZnO/Si structure as a packageless sensor sensitive to temperature with the ability to protect itself.

\section{CONCLUSION}

The ability to generate in the same heterostructure three propagation modes 0,1 and 2 of the acoustic wave, the confinement of the wave in the structure and good compatibility of the results obtained in simulation to experiment have been demonstrated. The characterization of the temperature behavior of the optimized heterostructure $\left(\mathrm{kh}_{\mathrm{ZnO}}=1.25\right)$, showed its potential as a temperature sensor. The measured TCF value is $-19.1 \mathrm{ppm} /{ }^{\circ} \mathrm{C}$. Finally the effective acoustic isolation of the wave within the heterostructure AlN / IDT / ZnO / Si has been demonstrated experimentally. Thus, this study allowed us to confirm the potential of the heterostructure AlN/IDT/ZnO/Si as the temperature sensitive device, having the ability to protect itself from air and moisture.

\section{REFERENCES}

[1] K. Bhattacharjee, A. Shvetsov, and S. Zhgoon, "Packageless SAW Devices with Isolated Layer Acoustic Waves (ILAW) and Waveguiding Layer Acoustic Waves (WLAW)", IEEE Freq. Control. Symp., pp. 135140, October 2007.

[2] O. Yamazaki, T. Mitsuyu and K. Wasa, "ZnO thin-film SAW devices", IEEE Trans. Son. Ultrason. Vol. SU-27, pp. 369-379, November 1980.

[3] Y.M. Lu, W.S. Hwang, W.Y.Liu and J.S. Yang, "Effect of RF power on optical and electrical properties of $\mathrm{ZnO}$ thin film by magnetron sputtering", Materials chemistry and Physics., Vol. 72 issue 3, pp. 269272, 2001.

[4] I. Sayago, M. Aleixandre, A. Martinez, M.J. Fernandez, J.P. Santos, J. Gutiérrez, I. Gracia and M.C. Horrillo, Synthetic Metals., Vol. 148, pp. 37-41, January 2005.

[5] T.E. Parker and C.J. Dunnrowicz, United States Patent 4270105 , "Stabilized Surface Acoustic Wave Device", May 1981.

[6] G.K Montress, T.E. Parker and D. Andres, "Review of SAW Oscillator performance”, IEEE Ultrason. Symp., vol. 43, pp. 43-54, 1994.

[7] D.E. Cullen and R.A. Wagner, United States Patent 4213104, "Vacuum Encapsulation for Surface Acoustic Wave (SAW) Device", July 1980.

[8] O. Elmazria, S. Zhgoon, L. Le Brizoual, F. Sarry, D. Tsimbal and M.A. Djouadi, "AlN/ZnO/Diamond Structure Combining Isolated and Surface Acoustic Waves", Appl. Phys. Lett, Vol. 95, pp. 233503-3, December 2009.

[9] O. Legrani, O. Elmazria, S. Zhgoon, P. Pigeat and A. Bartasyte, "Packageless AlN/ZnO/Si Structure for SAW Devices Applications", IEEE Sensors Journal, vol. 13, p. 487-491, February 2013

[10] K. Tsubouchi, K. Sugai and N. Mikoshiba, "AlN material constants evaluation and SAW properties on $\mathrm{A} 1 \mathrm{~N} / \mathrm{A}_{2} \mathrm{O}_{3}$ and $\mathrm{AlN} / \mathrm{Si}$ ", IEEE Ultrason. Symp., pp.375-380, 1981.

[11] [24] G. Carlotti, F. S. Hickernellh,. M. Liaw, L. Palmiergi, G. Socino and E. Verona, "The Elastic constants of sputtered aluminium Nitride Films", IEEE Ultrason. Symp., pp. 353-356, November 1995.

[12] [25] G. Carlotti, G. Socino, A. Petri and E. Verona, "Acoustic investigation of the elastic properties of $\mathrm{ZnO}$ films", Appl. phys. Lett. vol. 51, pp. 1889-1891, October 1987. 